\title{
BIOGRAPHY AND STORYTELLING: A IDENTIDADE E A SUBJETIVIDADE NA AULA DE INGLÊS NO IFA/FIVU
}

\author{
Biography and storytelling: identity and subjectivity in the English \\ classroom at IFA/FIVU
}

\author{
Leticia Pilger da SILVA \\ Universidade Federal do Paraná \\ leticiaspilger@gmail.com \\ https://orcid.org/0000-0002-1999-7336 \\ Valentina Thibes DALFOVO \\ Universidade Federal do Paraná \\ valentinadalfovo@outlook.com \\ https://orcid.org/0000-0003-1750-9412
}

\begin{abstract}
RESUMO: O objetivo deste artigo é analisar a construção da identidade e a implicação de subjetividade em duas Unidades Temáticas (UTs) criadas e aplicadas nas aulas de língua inglesa, dos níveis 2 e 4 , no projeto IFA/FIVU, sobre biografias e contação de histórias. Para isso, primeiramente, apresentaremos a concepção e o percurso da criação dos dois materiais didáticos; em seguida, delimitaremos o embasamento teórico sobre subjetividade e importância da alteridade para a constituição da identidade. Por fim, analisaremos atividades das duas UTs, observando o continuum de subjetividades na sua aproximação, que auxiliou o processo de aprendizagem: os "outros famosos", quando aparecem textos sobre vidas de celebridades dentro do material; os "outros desconhecidos", a partir da biografia e das narrativas de participantes da página $\mathrm{Hu}$ mans of New York, e, finalmente, os "outros dos outros", ou seja, o "eu", pela construção autobiográfica dos próprios alunos na língua inglesa. PALAVRAS-CHAVE: Língua Inglesa; Identidade; Subjetividade; Alteridade.
\end{abstract}

ABSTRACT: This article aims to analyze the identity construction and the implication of subjectivity in two Thematic Unities (TUs) developed and applied in the context of IFA/FIVU's English classes, level 2 and 4 . The themes of the unities are biography and storytelling. For that matter, firstly, the process of the conception and creation of the materials will be presented. Next, a theoretical approach to subjectivity and the importance of alterity to the constitution of identity will be

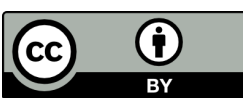


discussed.Lastly, theactivities proposedinthetwoUnities willbeanalyzed and compared to show a continuum of subjectivities in their connection, that helped the process of learning: the "famous others", celebrities and well-known people; the "unknown others", people from Humans of New York, and, finally, "the others of the others", which means, the "self" presented in the autobiographical construction of the students of English. KEYWORDS: English language; Identity; Subjectivity; Alterity.

\section{O COMEÇO DE UMA HISTÓRIA}

The consequence of a single story is this: it robs people's dignity. It makes the recognition of our equal humanity difficult. It emphasizes how we are different, rather than how we are similar. (Chimamanda Ngozi Adichie)

The fourth pillar is storytelling. The story you tell yourself about yourself, creating a narrative of the events of your life brings clarity and helps you understand how you became you. (Emily Esfahani Smith).

Trazemos, como epígrafes deste artigo que se escreve como um ensaio a quatro mãos e duas autobiografias ${ }^{1}$, trechos sobre histórias porque nós duas, mulheres que pesquisam literatura e ensinam línguas, vamos problematizar nossos percursos como praticantes $^{2}$ no IFA $^{3}$ a partir da montagem e do relato da aplicação de duas Unidades Temáticas (UT) construídas sobre dois temas que se tocam: Biography e The importance of a good storytelling. Contar as nossas histórias, como diz Emily Esfahani Smith (2017), é um pilar para entendermos como nos tornamos quem somos - no nosso caso, tanto como pessoas quanto como professoras. Pensando no contexto da sala de aula e da interculturalidade necessária no aprendizado de uma língua, o ato de contar

\footnotetext{
${ }^{1}$ A escolha da escrita como uma narrativa autobiográfica parte da metodologia das narrativas na linguística aplicada (NUNAN; CHOI, 2010; 2011), para a qual a "voz" e a "reflexividade" são importantes para se pensar o ensino-aprendizado da língua estrangeira. Dessa forma, este texto não é apenas um relato, mas uma dupla narrativa autobiográfica através da qual tentamos pensar a nossa identidade e a subjetividade da posição docente.

${ }^{2}$ Os alunos das disciplinas de prática que ministram as aulas no projeto são assim chamados.

${ }^{3}$ Como o projeto foi ficando cada vez mais conhecido, os alunos em geral passaram a chamá-lo de Idiomas para Fins Acadêmicos (IFA), já que o nome oficial (Formação em Línguas para Fins Acadêmicos) era muito longo. Esse nome fantasia - IFA — passou a fazer parte da identidade do projeto.
}

Revista X, v. 16, n. 4, p. 1011-1037, 2021. 
histórias — no plural — também ganha destaque, pois, como afirma Chimamanda Ngozi Adichie (2014), está relacionado ao poder sobre a vida que nos salva do perigo de contar uma história única e, consequentemente, de afirmar estereótipos, já que cada história tem uma perspectiva, assim como cada língua é cultura(s) - e também várias dentro de uma (GIMENEZ, 2001).

Como a sala de aula é um entrelugar linguístico-cultural no qual várias narrativas se chocam e dialogam, nesse espaço, o conflito se dá também entre as várias identidades e subjetividades envolvidas, sejam as dos professores, as dos estudantes, ou as dos povos falantes da língua estudada, bem como as dos autores e autoras das histórias (forjadas ou autênticas) dos materiais didáticos. A partir disso, nesse artigo, vamos analisar, através do nosso percurso como praticantes nas disciplinas de Prática I e II e do estágio no IFA, a subjetividade implicada - como professoras em formação (e agora em formação continuada), sejam as das vidas que colocamos no material, sejam as dos alunos que estavam aprendendo o inglês conosco - em duas Unidades Temáticas que criamos. Para isso, primeiramente apresentaremos a concepção e o percurso da criação dos dois materiais didáticos; em seguida, delimitaremos o embasamento teórico sobre subjetividade, importância da alteridade para a constituição da identidade (HALL, 2007; AUTHIER-REVUZ, 1990; JOUVE, 2013; MORRISON, 2017) e interculturalidade (GIMENEZ, 2001; BHABHA, 1998), que nos guiaram para pensar a criação do material e sua análise; por fim, analisaremos partes dos materiais, apresentando as atividades e analisando como ocorre um continuum de sujeito na leitura conjunta dos dois materiais: começamos abordando pessoas famosas para, em um segundo momento, falarmos de pessoas anônimas e, por fim, explorarmos a própria identidade dos alunos.

Comecemos, então, com nossas histórias no projeto, os sujeitos autoras e professoras. Eu, Letícia, participei do IFA/FIVU no meu último ano da graduação, em 2017. Apesar de cursar licenciatura dupla em Português e Inglês, eu só me via trabalhando com ensino de língua estrangeira no ambiente da escola pública, e o IFA me mostrou uma nova possibilidade, tanto pela metodologia quanto pelo público. No primeiro semestre daquele ano, fui observadora das aulas dos praticantes e acompanhei o desenrolar de duas turmas do nível 1 e 3. Enquanto "aquela que vê", fui coletando fotografias de possíveis atividades, materiais e interações. A partir das observações, os colegas praticantes também deram acabamento 4 à minha prática docente, pois me

\footnotetext{
${ }^{4}$ Menção ao conceito de exotopia, de Bakhtin (2000), em diálogo com as discussões de Henrique Janzen em sala de aula de Metodologia e nos seus textos discutidos quando fomos criar nossas UTs (JANZEN, 2008; 2010; 2011).
} 
apresentaram metodologias e atividades que desconhecia e as quais antropofagizei, apropriando para minhas aulas no projeto ${ }^{5}$.

No segundo semestre, fui professora regente da turma do nível 2 e apliquei várias UTs, como a analisada aqui, sobre biografias, que foi criada com a parceria da praticante Mariana Paiva ${ }^{6}$. A ideia dessa UT foi criada com o objetivo de apresentar o tempo verbal Simple Past, dialogar com os temas das UTs que havíamos criado previamente, além de trazer pessoas reais para a sala de aula, e não personagens anônimos e achatados, pensando na importância da implicação da subjetividade dos alunos dentro da aula para construírem-se (afinal, estamos em constante formação) enquanto construíam seus conhecimentos da língua e das culturas.

Já eu, Valentina, participei do IFA durante o último semestre de 2017 e o ano de 2018. Nessa circunstância, não encarava o ensino de línguas como uma pretensão pessoal, ainda que em graduação dupla de Português e Inglês. Antes da prática, o ensino de línguas estrangeiras ainda conservava para mim o mesmo direcionamento que eu recebi enquanto ainda fora da graduação e que pouco me interessava: o trabalho com a língua era objetivo e implicava muito pouco da minha identidade, dizia mais respeito a um conteúdo de domínio teórico, não necessariamente vivido.

Em 2017, no entanto, comecei efetivamente a ter contato com aulas de línguas dentro do IFA, em conjunto com discussões teóricas. De maneira mais esporádica, no segundo semestre, ainda para aprofundar conceitos das aulas de metodologia de ensino, acompanhei algumas aulas como observadora, inclusive, aulas da Letícia já como ministrante. Em 2018, tive a chance de atuar efetivamente como ministrante das aulas no nível 4. Durante todo esse processo, a UT que será aqui analisada, "A importância do Storytelling", vinha sendo desenvolvida, enquanto, junto a quem dividia as aulas, Rebeca Lessman, analisava e aplicava outras UTs disponíveis nos arquivos do IFA. Enquanto praticante efetivamente, já no último semestre da graduação, pude começar a colocar em uso o que havia percebido nos momentos de observação e testar hipóteses, como a de que a subjetividade e a capacidade de o aluno se (re)conhecer nas aulas são fundamentais no processo de aprendizagem.

\footnotetext{
${ }^{5}$ Pensando na construção constante de nossa identidade, decidimos colocar em itálico, como fronteira da enunciação, trechos de nossos relatórios finais de Prática II, de modo a mesclar outros-eus nossos às nossas vozes de hoje e mostrar como ressoamos a nossa experiência anos depois pela escrita e pela análise.

${ }^{6}$ Aproveitamos o espaço para agradecer a Mariana Paiva, pela parceria na confecção do material e pela autorização da realização desta análise de nosso material. 
Todas essas oportunidades foram muito ricas e conduziram nossa compreensão acerca da importância de subjetividades em sala de aula: em um primeiro momento, da própria professora ou professor, que precisa criar o ambiente do ensino; depois, de cada um dos indivíduos que está aprendendo, dentro do seu próprio contexto particular, a integrar na sua prática uma nova faceta de expressão que acompanha o aprendizado de uma nova língua. Considerações como a riqueza da mistura de perspectivas são relevantes nos nossos relatórios, e a alteridade é um ponto de crescimento que marcou a prática que experimentamos no IFA: poder pensar o material do plano de aula discutindo as ideias tornou a aula muito mais rica e possibilitou misturar diferentes atividades, conforme as preferências de cada uma (das praticantes).

Assim, podemos afirmar que o processo de compreensão da necessidade do espaço para a construção da identidade dos alunos se deu concomitantemente à formação da nossa identidade enquanto professoras de inglês. Formação essa sempre em contato com e diante de alteridades, considerando que a nossa formação enquanto sujeito (eu) só se dá em coexistência com o outro (ela/ele), relação de extrema importância no processo de aprendizagem. Na prática de ensino no IFA, pudemos tocar n'A experiência maior de que fala Clarice Lispector em uma crônica (1999, p. 385): "Eu antes tinha querido ser os outros para conhecer o que não era eu. Entendi então que eu já tinha sido os outros e isso era fácil. Minha experiência maior seria ser o outro dos outros: e o outro dos outros era eu". E é esse outro em outra língua que queremos pensar aqui através da construção e da aplicação do material didático.

\section{CAMINHOS TRILHADOS: EMBASAMENTOS DE NOSSAS CONSTRUÇÕES}

Fomos apresentadas ao conceito geral da UT, enquanto um material que apresenta a língua e seus usos e estruturas de maneira contextualizada em determinado tema, na disciplina de Metodologia de Ensino de Língua Estrangeira. Depois da análise detida de outros materiais didáticos e da leitura e discussão de textos teóricos para embasarem nosso trabalho, nos foi solicitado que começássemos a pensar na produção de uma unidade temática, cujo desenvolvimento se dava com o intuito final de sua aplicação no contexto do IFA. É interessante, nesse sentido, pensar o material didático a partir de categorias mais objetivas que nos permitam julgar o nosso espaço de criação, pois, como apresenta Renato Caixeta da Silva (2017, p. 143-144): "Para docentes de inglês, em específico, ele [o material didático] é fonte, agente, facilitador, suporte, organizador, atração, guia, curso, mercadoria e possibilidade.". A partir das nossas narrativas, fica visível que o IFA configurou, para nós, um contexto de ensino-aprendizagem ideal se comparado 
a escolas regulares e a cursos de idiomas, uma vez que houve um direcionamento e uma distribuição de tempo que nos permitiram desenvolver os materiais de maneira descompromissada com categorias como mercadoria e radicalmente enquadradas na ideia de possibilidade, visto que as UTs são sempre um desenvolvimento específico para aquele contexto - mais do que uma possibilidade entre muitas, a possibilidade desejada. Assim, concordamos com Jovania Santos, quando relembra que todo o contexto de produção influencia o resultado:

O desafio de refletir sobre os enunciados de tarefas envolve não apenas o enunciado em si, mas todo o entorno em que se insere. Não se elaboram tarefas isoladamente. Elas fazem parte de uma sequência de trabalho ou acompanham um texto como disparador da proposta de produção. Além disso, estão conectados por um programa de curso, sua concepção teórica, pelas perspectivas teóricas da instituição de ensino e pela relação de poder entre os participantes do ato comunicativo. (SANTOS, 2014, p. 58).

A produção de nossas UTs suscitou, para nós, a percepção de que as UTs são espaço rico para as subjetividades, tanto no que diz respeito à autoria, visto que sua criação demanda criatividade e se configura, segundo Jovania Santos (2014, p. 58), como um exercício de alteridade, quanto pela necessidade de nos colocarmos - como mediadores - no lugar do outro que realizará as atividades, por ser também espaço sobre o qual os alunos se recriarão como sujeitos ativos na construção do conhecimento da língua estudada e no qual acontecerá o intercâmbio de significações. Os professores que criam as atividades precisam, apesar de não preverem totalmente, especular as possíveis significações dos alunos quando em contato com o tema e com os textos selecionados. A autoria das UTs pensa, dessa forma, a subjetividade e a agência dos alunos - nesse caso, de estudantes universitários da própria universidade - no processo de ensino-aprendizagem, para que tenham autonomia discursiva na interação socioverbal (PICANÇO, 2002).

A identidade, na concepção adotada por nós, diz respeito, no contexto em que vivemos, a uma categoria interativa e em constante construção, porque, como apresenta Stuart Hall (2007), o sujeito monolítico e de identidade fixa sofreu cinco 
grandes descentramentos do discurso ${ }^{7}$ que tornaram a identidade deslocada, híbrida e fragmentada. Como apresenta Hall, a psicanálise, um desses descentramentos, trouxe a ideia de que somos divididos dentro de nós mesmos, com consciente e inconsciente, além de que, devido à crise das estruturas das sociedades modernas e à crescente complexidade do mundo, viu-se uma fragmentação e descentramento do sujeito moderno, o que fez com que nosso entendimento de nós mesmos enquanto sujeitos unificados fosse abalado (HALL, 2007; 2010). Somos vários eus na nossa própria língua materna (que por si só já é várias) e somos diferentes conforme os contextos em que vivemos e as interseccionalidades de gênero, etnia, classe, geração e sexualidade. Segundo Hall (2007, p. 39), “a identidade surge não tanto da plenitude da identidade que já está dentro de nós como indivíduos, mas de uma falta de inteireza que é 'preenchida' a partir de nosso exterior, pelas formas através das quais nós imaginamos ser vistos pelos outros.".

Na constituição da identidade, o sujeito constitui sua subjetividade pela alteridade, ou seja, na interação social pela linguagem, visto que se diz eu na interação com o(s) outro(s), que, por sua vez, também são sujeitos. Como afirma Jacqueline Authier-Revuz (1990), há uma heterogeneidade constitutiva da subjetividade, por um lado, na diferença do sujeito com ele mesmo, na sua interioridade - consciente e inconsciente; por outro, na discursividade, pois para um "eu" existir ele precisa ser interpelado por um outro que se diz eu. Assim, ser sujeito é ser um ser de e na linguagem. A língua estrangeira — como adicional, no processo de desestrangeiração da língua — faz parte dessa interatividade que nos constitui enquanto sujeitos.

Quando pensamos o processo de ensino-aprendizagem de uma língua adicional, somos deslocados na língua por outro(s) sujeito(s) em sala de aula e nos materiais, didáticos ou autênticos, e por significações através dos quais precisamos nos repensar e narrar a vida com outra voz de nós mesmos. Daí a importância de usarmos materiais autênticos, enquanto enunciados (unidade de comunicação) e gêneros textuais em uso (modelos de enunciados estáveis nos usos discursivos), já que fazem com que os alunos tenham contato com a língua em contextos socio verbais reais, inclusive considerando o contexto extra verbal (BAKHTIN, 2000).

\footnotetext{
${ }^{7}$ Para Hall (2007), houve cinco descentramentos no discurso sobre o conhecimento que culminaram no descentramento do sujeito moderno: o marxismo e seu deslocamento da agência individual para o âmbito coletivo; a psicanálise, com a descoberta do inconsciente e com a inserção da palavra "identificação" para pensar a identidade como processo; a linguística, com a enunciação e a polifonia; a genealogia do poder de Michel Foucault, com a sujeição e a subjetivação da formação do sujeito, e, por fim, o feminismo, tanto como crítica teórica e como movimento social, que deu força à política de identidades e a interseccionalidade entre gênero, etnia e classe.
} 
A partir de materiais autênticos, os alunos podem reconstruir sua subjetividade e repensar suas identidades, em diálogo, em sala, com os professores e com os demais alunos, tendo em vista que as significações de um mesmo texto podem ser distintas dadas as experiências subjetivas de cada um. Nesse sentido, e pensando que ensinar e aprender línguas é aprender e ensinar culturas, é essencial problematizarmos a constituição das identidades culturais, porque as relações entre global e local estão cada vez mais imbricadas no nosso mundo globalizado, com culturas cada vez mais híbridas e sujeitos mais deslocados, territorial e linguisticamente. No entanto, como afirma Toni Morrison (2017), precisamos sempre ter em mente que esse não é um processo inocente: no discurso de desprezar as fronteiras nacionais e os idiomas, acelera-se "o apagamento, em um aplainamento de diferenças importantes" (MORRISON, 2017, s. p.), como as margens e os indivíduos marginalizados. Esses tornam-se exemplos de seu termo outremização, que fala sobre a construção do outro, em oposição ao sujeito, de maneira achatada e desumana, baseado, na maioria das vezes, em estereótipos, o que faz com que esse outro não seja um eu que nos interpele.

$\mathrm{Na}$ sala de aula, os alunos não podem ser outremizados de forma a serem tidos como sujeitos passivos e receptáculos da língua que estudam. No contexto de ensino de inglês como língua estrangeira, pensamos ser importante, portanto, problematizar o ensino muito baseado apenas nos países do círculo interno do esquema de $\mathrm{Kachru}^{8}$, como Estados Unidos e Inglaterra. Essa é uma violência que reforça o imperialismo linguístico e, consequentemente, uma narrativa única sobre as diversas culturas que falam inglês, que não gostaríamos de incorrer para não apresentarmos um foco no mítico falante nativo como um modelo a ser copiado pelo aprendiz (GIMENEZ, 2002).

Essa preocupação envolve, também, pensar a outremização dos personagens de livros didáticos, que muitas vezes são planos e achatados, como que desenhos e narrativas forjadas para o contexto e que apresentam apenas um nome, uma profissão, e muitas vezes uma vida perfeita, sem qualquer verossimilhança que possibilite um diálogo entre

\footnotetext{
${ }^{8}$ O Círculo de Kachru é um diagrama formado por círculos que mostra a influência dos países de língua inglesa e que mostra a abrangência do inglês como língua internacional. No inner circle, o epicentro do diagrama, estão os países do imperialismo linguístico, antigos colonizadores que seguem na época da decoloniedade hegemônicos - estão Estados Unidos, Reino Unido e Austrália; no outer circle, estão os países que foram colonizados e que tiveram a língua inglesa imposta, como Índia, Singapura, Nigéria, já no expanding circle, estão os países que usam a língua internacionalmente, como é o caso do Brasil, da China e da Rússia. A crença de que os países do inner circle são superiores propaga o mito do falante nativo e faz com que os aprendizes queiram ser como o "outro", solapando a própria identidade, colocando-se no lugar de um "outro" e "outremizando" as diversas possibilidades de se ser falante da língua inglesa.
}

Revista X, v. 16, n. 4, p. 1011-1037, 2021. 
realidades - a da cultura da língua estudada com a daquele que a estuda (JANZEN, 2008, 2011). Ou seja, não são espaço para subjetividade, mas reafirmam estereótipos e visões monolíticas da(s) cultura(s) da língua estrangeira, que segue sendo a língua do outro, e não uma faceta adicional da identidade do estudante.

Em contrapartida, em uma perspectiva intercultural que compreende que língua é cultura - ou linguacultura (GIMENEZ, 2001) — é necessário valorizar as diferenças, sem dominação, e ressignificar ambas as culturas durante a aprendizagem da língua estrangeira, considerando que "O ensino de línguas estrangeiras, como campo de disputas simbólicas, pelo confronto inevitável com a diferença - que gera diferença - e hibridização de culturas, e como espaço de socialização de signos identitários". (PICANÇO, 2012, p. 117).

Nesse contato entre culturas e sujeitos, portanto, acontecem deslocamentos do nosso eixo identitário ao fazermos uma tradução cultural e criarmos o que Homi Bhabha (1998) chama de um terceiro espaço, um entrelugar: não uma intersecção ou um mero contato entre dois espaços-culturas, mas a criação de uma terceira margem, um diálogo que nos constitui através da alteridade de outros sujeitos como uma hibridação. Tentamos pensar a sala de aula, nesse caso, como um espaço intermediário (GIMENEZ, 2001) no qual a identidade se ressignifica entre sujeitos. Ao pensarmos a identidade nesse viés, temos deslocamentos diversos, de modo que a aula de língua estrangeira se mostra um espaço rico para a desconstrução dessa outremização, desse achatamento, para que pensemos em outros que se dizem eu e também para podermos dizer eu de formas diferentes: eu/I e nós/we.

A partir disso, podemos dizer que pensamos as UTs como espaços de subjetividades e, de certa maneira, criadoras desse terceiro espaço, visto que há um deslocamento entre culturas e uma ressignificação da subjetividade dos alunos. Criamos as UTS, assim, calcadas na crença de que quando o material passa do conhecido do aluno para o novo, em contato com temas relevantes e atividades que solicitem a produção de diversos tipos de textos e trabalhe com realidades autênticas, há uma valorização da sua agência e mais espaço para que a aprendizagem ocorra de maneira efetiva.

\section{A EXPERIÊNCIA COM AS UTS: UMA COMPARAÇÃO DE PROCESSOS E SEUS RESULTADOS}

A UT Biography foi construída a partir de duas unidades de nossa autoria Letícia e Mariana - para suprir a necessidade de mais material para o nível 2, e se mostrou uma experiência não de reelaboração das UTs, mas de adaptação e de ressignificação dos 
textos. Minha UT prévia, que fez parte dessa como substrato, tematizava a importância da identidade em retratos e autorretratos, e a de Mariana Paiva tratava sobre a literatura de Chimamanda Ngozi Adichie. Enquanto eu, Letícia, e Mariana a construíamos e trabalhávamos com outras UTs do acervo do IFA, ressignificamos textos e sentidos. Ao compararmos nossas primeiras UTs à da Biography, percebemos como é mais desafiador construir material didático para os níveis iniciais com materiais autênticos e como o exercício de alteridade é mais trabalhoso, porque é preciso pensar em comandos e textos que agreguem conhecimentos, mas, ao mesmo tempo, não se mostrem muito difíceis para os alunos que estão começando a aprender a língua.

Quanto à minha trajetória, eu, Valentina, por afinidade, optei, juntamente de Rebeca Lessman, por trabalhar com UTs que envolvessem de alguma maneira a ideia de identidade. Por um interesse mútuo em literatura também, as escolhas se deram pautadas na ideia de trazer conteúdos que colaborassem para a construção do sujeito leitor que embasasse um subsequente sujeito falante. Iremos nos deter para pensar a questão da identidade na UT The importance of a good storytelling, no nível 49.

Ainda antes de começar as análises devidamente, é válido mencionar a importância do processo de construção da UT que aqui exemplificamos a partir de meu relato pessoal, mas que também são reverberações da experiência da Letícia. Durante o processo de aulas já mencionado, em paralelo, pude contar com a orientação por parte de diferentes professores da universidade, em diferentes disciplinas. O que, segundo meus relatórios, pareceu bastante positivo por configurar um movimento de soma de subjetividades: $A$ possibilidade de continuar a produção de uma mesma unidade temática da matéria de metodologia foi muito interessante, ainda mais por as professoras das matérias terem visões diferentes sobre. Acredito que as opiniões conflitantes me fizeram expandir as possibilidades da unidade e combinar maneiras de pensar que provavelmente eu não combinaria se passasse por apenas um professor.

Nesse sentido, também é importante mencionarmos que o processo de maturação da UT em diferentes momentos da trajetória nas disciplinas de prática e no IFA deixou marcas muito interessantes no que concerne à percepção do equilíbrio necessário em sala entre a sistematização requerida para a veiculação do conhecimento e a flexibilidade

\footnotetext{
${ }^{9}$ Para fins de explicação: na primeira, experimentamos a composição de uma narrativa que implicasse o próprio sujeito por meio das suas conclusões. Na segunda, partimos de um repertório literário para a compreensão de narrativas de vida. Na terceira, exploramos dilemas éticos que exigiam dos alunos uma postura pessoal de resposta. Na última, de minha autoria, falamos efetivamente da importância da construção de uma narrativa pessoal enquanto discutíamos a competência linguística de coesão e coerência narrativa.
} 
almejada para comportar expressões muito particulares de cada um: Ainda, o processo foi interessante, pois em metodologia as orientações foram mais gerais e abrangentes, resultando em uma unidade temática mais voltada para a subjetividade do aluno, o que é muito necessário no trabalho em sala. A disciplina de prática, no entanto, com o auxílio das fichas técnicas de avaliação da UT, me fez voltar para a unidade temática procurando nela também suas capacidades objetivas, como objetivos discursivos. Ou seja, trabalhando em contínuo, acho que foi possivel ao menos tentar desenvolver uma UT que conciliasse a subjetividade do aluno com a objetividade necessária à sistematização de conteúdo em sala de aula.

Dessa forma, percebemos que as conversas (de orientação, entre colegas...) colaboraram com um produto que, ainda que individual enquanto produção nossa, aconteceu como acontece a formação identitária quando se vive em sociedade: em conversa com alteridades. Como afirma Janzen (2011, p. 671): “A reelaboração de atividades pedagógicas, a partir da perspectiva dos interlocutores e com vista à interlocução, pode, nesse sentido, auxiliar na construção (posterior) de novos sentidos". Dessa forma, todo o processo, da maturação das ideias, passando pela produção dos materiais, até a sua aplicação e assimilação, é constituído de interações que os constroem de maneira mais ou menos direta. Recriamos esse movimento nesta escrita, enquanto duas que dialogam sobre a prática no IFA/FIVU em uma equivocidade (vozes que se misturam, mas que não se sobrepõem), um agenciamento coletivo de vozes ${ }^{10}$.

A começar pelos títulos das UTs analisadas, iremos, agora, aproximar algumas atividades de ambas para pensar como ocorrem as implicações subjetivas presentes dentro do material didático como outros que nos fazem dizer $e u$, pensando nossos objetivos durante a construção e os resultados. Em um continuum, falaremos das subjetividades exploradas nos materiais, passando de pessoas famosas para pessoas anônimas e, por fim, para a exploração da própria identidade dos alunos. Nesse continuum, há um intercâmbio entre conhecimentos e discursos entre os dois materiais por serem aplicados em dois níveis diferentes de inglês no IFA. As UTs Biography e The importance of a good story telling são construídas com a presença de narrativas autênticas que conduzem para a compreensão de que uma (auto)biografia se constrói sobre a capacidade bem exercitada de narrar uma história, do outro, e da sua própria.

\footnotetext{
10 Trazemos o conceito de "agenciamento coletivo" para dialogar com a enunciação para Gilles Deleuze e Felix Guatarri (1995), para os quais não há discurso direto, mas uma concatenação de discursos diretos, porque em cada nova enunciação o enunciado é novo. A UT é essa concatenação de discursos, pois selecionamos trechos de textos e de práticas que já nos perpassaram, que perpassarão os alunos e, em outras aplicações, outros professores e mais alunos.
} 
A UT Biography, construída com base na vida de pessoas famosas, contextualiza o tema, inicialmente, pelo filme Pelé: the birth of a legend (2016 - lançado no Brasil em setembro de 2017), baseado na vida do jogador brasileiro, com o objetivo de pensar a identidade a partir de uma figura conhecida pelos alunos e tocar na relação entre cinema e biografia. Antes de o trailer do filme ser visto, nós, professoras, abrimos uma breve discussão perguntando aos alunos "Do you like to watch movies based on TRUE STORIES?" [Você gosta de assistir filmes baseados em histórias reais?] e "Have you ever watched the movie 'the birth of a legend"?" [Você já assistiu ao filme "O nascimento de uma lenda"?], perscrutando o que são consideradas "histórias reais" para os estudantes. Além disso, passamos o trailer legendado em inglês para que pensassem a realidade brasileira deslocada para a língua estrangeira - e mobilizassem uma reflexão intercultural - , ao que muitos relataram que foi uma experiência estranha por terem visto e ouvido em inglês uma referência brasileira construída em suas vidas em português, o que mostra uma expansão do próprio mundo por meio da cultura da língua estudada através de uma ressignificação das próprias referências entre línguas e nega a história única da língua inglesa como a língua do outro. A vida de um brasileiro em inglês mostrou a eles que podem também narrar a si mesmos na língua que estavam aprendendo - o que de fato fazem no nível 4, com a segunda UT.

Em seguida, realizamos o jogo "Guess who?" (Adivinha quem?) com cinco pessoas famosas. Novamente, o objetivo era partir do conhecido do aluno para que focassem na compreensão das frases da atividade sem que se sentissem acuados por causa de palavras ou estruturas desconhecidas. O jogo foi composto por três etapas: primeiro, os alunos, individualmente ou em pequenos grupos, tentaram descobrir quais eram as pessoas descritas (Anexo 1): Neymar, J.K. Rowling, Frida Kahlo e John Lennon. Selecionamos pessoas bastante conhecidas de diferentes nacionalidades para que eles pensassem, como no trailer, o inglês como uma língua entre vidas, uma língua que une pessoas - tendo em vista a importância da função do inglês como língua franca e língua internacional na atualidade, pensando no expanding circle $^{11}$ e nas possibilidades de um "inglês brasileiro". Na compreensão do inglês como língua internacional, para Aya Matsuda e Patricia Friedrich:

O objetivo de usar inglês não é somente aprender dos outros, como nós costumávamos acreditar no passado. Nosso objetivo agora é estabelecer e manter uma relação igual e respeitosa com os outros, que requer a habilidade de perceber e analisar o familiar a partir de outra

\footnotetext{
${ }^{11}$ Reler nota 9 para retomar explicação do conceito no Círculo de Kachru. 
perspectiva [...] empoderando os estudantes com lentes críticas que lhe permitam usar o inglês efetivamente para resolver suas próprias necessidades enquanto respeitando as necessidades dos outros. (MATSUDA; FRIEDRICH, 2011, p. 340, tradução nossa) ${ }^{12}$.

Além disso, esses outros famosos, enquanto figuras públicas, foram selecionados como exemplos de possibilidades de vidas e como mote para que os alunos pensem no anonimato gerado pela ausência de um nome antes de serem traçados os pontos dos fatos biográficos, assim como nas semelhanças e diferenças de narrativas biográficas de cada um. Ou seja, o anonimato da vida pública sem um nome. A partir daquelas vidas conhecidas, pudemos pensar: como nossas vidas, como brasileiros e como estudantes universitários da UFPR, se parecem ou diferem? ${ }^{13}$ E o que faz daquelas vidas conhecidas?

$\mathrm{Na}$ segunda parte, com base na leitura das frases da etapa anterior, os alunos tinham que colocar os termos das frases na ordem correta para descobrirem quem eram as pessoas (Anne Frank e Rodrigo Hilbert), como se precisassem ordenar a biografia alheia, dando-lhes acabamento e as significando enquanto vidas. Por último, eles precisavam criar frases sobre outras pessoas famosas de sua escolha - com nosso auxílio para pensarem em estrutura e vocabulário. Esse material desenvolvido por eles foi utilizado para realizar o jogo com os colegas; cada um leu em voz alta suas frases para que os outros tentassem descobrir quem era a pessoa conhecida descrita. A atividade não apenas fez da aula uma equivocidade de vozes diversas (se) falando, mas também fez essas vozes serem voltadas à alteridade por almejarem a compreensão do raciocínio do outro, porque cada aluno tentava fazer-se entender e, ao mesmo tempo, entender o que os outros diziam, ajudando-se entre si, apesar de suas dificuldades e inseguranças.

Tendo em vista nossa perspectiva, que desloca a velha compreensão do idioma estudado como "falar e ser como o outro", a maioria dos personagens descritos eram personalidades brasileiras e latino-americanas, e até figuras curitibanas famosas como o

\footnotetext{
${ }^{12}$ No original: "The purpose of using English is not solely to learn from others, as we may have believed in the past. Our goal now is to establish and maintain an equal, mutually respectful relationship with others, which requires the ability to perceive and analyze the familiar with an outsider's perspective." (MATSUDA; FRIEDRICH, 2011, p. 340).

${ }^{13}$ Não exploraremos aqui, pela dimensão do texto, mas podemos pensar a figura da personalidade famosa a partir do conceito de ficção como uma "antropologia especulativa" de Juan José Saer (2009), porque as biografias das celebridades são, antes de tudo, uma especulação de possibilidades de vidas públicas e por isso são abertas à ficcionalização, e até mesmo de um achatamento da privacidade, como se ser famoso fosse ser uma personagem. No livro didático, eles são especulações biográficas no deslocamento linguístico, recortes da realidade.
}

Revista X, v. 16, n. 4, p. 1011-1037, 2021. 
Oil Man. Acreditamos que a presença de Rodrigo Hilbert no material foi determinante para que os estudantes selecionassem pessoas mais locais, como uma resposta ao material.

De acordo com o relato deles, não esperavam que aparecesse um famoso tão "específico" no meio do material didático de inglês, já que os demais famosos têm abrangência e Frida Kahlo, J. K. Rowling, John Lennon e Anne Frank aparecem em materiais didáticos, sejam de língua materna ou de língua estrangeira. Além disso, o verbo "to consider" na frase "a perfect - he - is considered - man - because he - cleans - cooks - the house - builds stuff — looks after his kids" permitiu que comentássemos sobre biografias através dos trabalhos domésticos e da diferença de gênero, o que fez com que eles partissem da vida do apresentador e modelo e compartilhassem suas perspectivas e suas vidas sobre o que seria uma "pessoa perfeita" e um "homem perfeito", considerando os papeis sociais de gênero - inclusive se concordavam com a visão de Hilbert como um "perfect man".

Depois, essa etapa do jogo também permitiu que os alunos mostrassem parte da sua identidade, porque fizeram uma biografia do "Eu/nós/we", trouxeram suas referências, seus ídolos, suas concepções de "famosos" e "pessoas conhecidas" e nos diziam sobre si e sobre os grupos sociais nos quais estão inseridos, repensando sua própria cultura através da língua estudada e sobre a própria construção de vida e de fama a partir de fatos biográficos de celebridades.

Foi uma espécie de biografia pela alteridade - um outrar-se sem uma outremização, um contato como na crônica clariceana que colocamos na introdução, do outro ser o caminho do eu. Afinal, tudo que escolhemos e fazemos conta um pouco de nós, como fez uma aluna de Letras-Espanhol. Ao reconstruir a biografia de Frida Kahlo em suas frases, na hora de enunciá-las verbalmente, falou "México" não em português, mas em espanhol, como se estivesse entrando na sua identidade deslocada para seu eu do castelhano. Nesse momento, a aluna nos mostrou as facetas linguísticas e identidades que a constituíam, porque ela habitava o espaço intermediário entre as três línguas e se mostrou um sujeito oblíquo e híbrido dentro de sua própria identidade ao se colocar na posição de sujeito da aprendizagem. Como afirma Sylvia Molloy (2019, p. 52, grifos da autora) sobre o bilinguismo, estar entre línguas escancara a "alteridade da linguagem", por mostrar que

[...] o que se faz está sempre sendo dito em outro lugar, em muitos lugares. Esta consciência da inerente estranheza de toda comunicação, este saber que o que se diz é desde sempre alheio, que o falar sempre implica insuficiência e sobretudo doblez (sempre há outra maneira 
de dizê-lo) é característica de qualquer linguagem, mas, na ânsia de estabelecer contato, esquecemos disso.

$\mathrm{Na}$ aprendizagem da língua estrangeira, ao rompermos as amarras e vivermos a língua, somos seres fronteiriços (ANZALDÚA, 2007) no entrelugar da tradução e do choque entre línguas e culturas.

Na sequência, colocamos o texto de apresentação do site da escritora nigeriana Chimamanda Ngozi Adichie. A partir da apresentação oral da escritora e da exibição de trechos de seu TED Talk sobre o perigo da história única, como atividade de preparação para a leitura, conversamos sobre as diversas culturas de língua inglesa para que eles pensassem no Círculo de Kachru e na visibilidade de produções de outros lugares que não o centro do imperialismo linguístico-cultural, além de pensarmos, em grupo, a importância da função do inglês como língua franca que permite a comunicação internacional e a expansão as nossas lentes sobre quem são esses "outros". Ela era uma Outra famosa que, pela falta de visibilidade das narrativas africanas - como ela mesma disse no seu TED Talk — , foi uma outra anônima para a maioria e mostrou, com isso, uma história diversa do que se pensa sobre o inglês na versão da "história única". Inclusive, em conversa sobre os dados do texto, apresentamos o romance Americanah (2014) - do qual a UT original de Mariana trazia um trecho que quebrava a visão americanizada e outremizada dos nigerianos - , e a descoberta da personagem nigeriana, quando chegou aos Estados Unidos, de que era negra e de como ela era vista como uma "outra", achatada e fora da posição do sujeito. A partir da biografia da Chimamanda, também discutimos com os alunos, pensando nessa outridade dos famosos em relação a nós, nossas referências de "famosos" (como conhecemos pessoas muito conhecidas? Quais ignoramos e por quê?), pensando como uns famosos são mais famosos que outros. A partir disso, pensamos as referências culturais e como lemos e consumimos, através de produtos culturais, culturas em língua inglesa.

Uma das atividades propostas a partir do texto foi que os alunos, em duplas, formassem perguntas sobre informações que faltavam no texto de Chimamanda. Como cada aluno tinha uma versão diferente do texto, com partes retiradas diferentes (ex.: um tinha uma lacuna no local onde ela nasceu, enquanto o outro não tinha a informação do primeiro livro publicado por ela), eles deveriam completar as informações retiradas da sua versão do texto-base a partir de formulação de perguntas para o outro, cujo material apresentava essas informações. Pela troca de informações, reconstruíram e completaram a vida (e a identidade) da escritora, uma outra - e um terceiro sujeito na conversa através de outros, visto que, como disse Bakhtin: 


\begin{abstract}
Nossa fala, isto é, nossos enunciados [...] estão repletos de palavras dos outros, caracterizadas, em graus variáveis, pela alteridade ou pela assimilação, caracterizadas, também em graus variáveis, por um emprego consciente e decalcado. As palavras dos outros introduzem sua própria expressividade, seu tom valorativo, que assimilamos, reestruturamos, modificamos. (BAKHTIN, 2000, p. 313-314).
\end{abstract}

Já na UT do Storytelling, aplicada no nível 4, as vidas primeiramente abordadas não foram mais as desses que aqui chamamos de "outros famosos", mas a vida dos "outros desconhecidos". Com isso, queremos apontar para a relação de alteridade um pouco diversa que se constrói, ainda que continue com o foco na ideia de identidade. A unidade tem como início a apresentação de três histórias retiradas do site Humans of New York $^{14}(\mathrm{HONY})^{15}$, que se propõe um espelho de realidades individuais, apresentando com uma foto e um texto curto, flashes da vida de desconhecidos, abordados na rua da cidade estadunidense. Em um primeiro momento, foi solicitado aos alunos que observassem as fotos apresentadas: a primeira, de um menino que relata uma experiência de apresentação no colégio; a segunda, de um pai jovem com seu filho pequeno, em que o pai relata com emoção um momento de declaração de amor do filho para ele; a terceira, de uma mulher jovem com um relato sobre suas conquistas do ano que se passou, em que se destaca que conseguiu tirar a licença para dirigir. A partir dessas fotos e dos respectivos textos, os alunos foram solicitados em dois momentos - antes e depois da leitura - a tentar inferir quem são aquelas pessoas e qual delas cada um julgava ser mais feliz.

O julgamento já compunha parte da nossa ideia de trabalhar com o exercício subjetivo, uma vez que exigia uma postura de inferência, principalmente antes da leitura, pois não havia dados suficientes que comprovassem a questão, apenas impressões depreendidas das imagens. O que eles tinham e que foi mobilizado é o que Vincent Jouve (2014) chama de "subjetividade necessária" para a leitura de um texto. Segundo ele, no ato da leitura existem lacunas que precisam ser preenchidas, bem como informações são pensadas a partir de imagens já gravadas em nossa memória. Uma pessoa extremamente feliz pode assumir características diferentes em diferentes imaginações, com referência ao vivido pessoal de cada indivíduo. Como pontua Jouve: “[...] cada um projeta um pouco de si na sua leitura, por isso a relação com a obra não significa somente sair de

\footnotetext{
${ }^{14}$ Disponível em: https://www.humansofnewyork.com/. Acesso em: 23 jun. 2020.

${ }^{15}$ A utilização dos textos desse site em materiais didáticos em outro projeto de ensino de inglês da nossa universidade, o PIBID-UFPR, mostra a relevância desses textos autênticos para ampliar a relação com outras culturas de forma a quebrar estereótipos. O projeto feito no CEP pode ser acessado aqui: http://www.cep.pr.gov.br/Noticia/Historias-e-experiencias-compartilhadas-emingles-e-portugues-pelo-Humans-CEP. Acesso em: 23 jun. 2020.
} 
si, mas também retornar a si. A leitura de um texto também é sempre a leitura de um sujeito por ele mesmo." (JOUVE, 2014, p. 53). Nesse sentido, as lacunas deixadas na atividade eram ainda maiores, para que os alunos se sentissem mais livres em argumentar como bem entendessem, tendo mais claro o fato de que não havia nada no texto que confirmasse categoricamente uma posição.

Vale mencionar que, diferentemente das vidas mobilizadas na UT analisada anteriormente, aqui as vidas são de realidade privada e apresentam uma proximidade de experiências que pareceu envolver os alunos. Uma das histórias, em especial, chamou atenção (Anexo 2): o relato da dificuldade e do medo em tirar a carteira de motorista pareceu ser uma demanda mais comum, que preocupava e efetivamente era uma questão na vida de alguns alunos, considerando que a faixa etária do público em sala girava em torno dos 20 anos e, portanto, haviam recentemente passado ou estavam planejando passar por situação semelhante. A partir dessa atividade, também foi trabalhado o objetivo de que os alunos começassem a se familiarizar com a ideia de narrar vidas.

Passado esse primeiro momento, eles foram apresentados a um vídeo ${ }^{16}$ que mobilizava a discussão seguinte: um Ted $\operatorname{Talk}^{17}$ de Emily Smith, pesquisadora de psicologia, neurociência e filosofia. No vídeo, ela trata de uma pesquisa que conduziu sob a inquietação: there is more to life than being happy [Há mais na vida do que ser feliz]e, ao narrar suas descobertas, ela mesma nos conduz através da sua própria autobiografia: nos conta de elementos desde a sua infância, até as descobertas apresentadas. Mais uma vez os alunos tiveram contato com construção textual semelhante ao que produziriam ao final.

Depois desse momento de inferência, a próxima seção, intitulada Connecting ideas, tinha por foco sistematizar o conhecimento apresentado até então de forma intuitiva. Em sala, sugerimos aos alunos a reflexão: Is there a coincidence among a good storytelling and the way the writer chooses to write it? [Há uma coincidência entre a qualidade de uma história e a maneira com o escritor escolhe narrá-la?]. Com isso, refletimos com eles como as ferramentas linguísticas são caminhos para se chegar à expressão identitária. Ainda com o intuito de sistematização, os alunos encontravam na UT também uma tabela em que puderam preencher de maneira organizada os conectivos separados por funções: introdução, conclusão, explicação etc. Tornamos, com isso,

\footnotetext{
${ }^{16}$ Considerando o nível de domínio da língua dos alunos, era interessante que o texto tivesse uma transcrição para que eles acompanhassem se necessário, bem como era interessante que a fala se estruturasse de maneira bastante organizada como é, subdividida em quatro tópicos, sendo o último deles justamente o storytelling (contação de história) pessoal.

${ }^{17}$ Disponível em: https://www.ted.com/talks/emily_esfahani_smith_there_s_more_to_life_than being_happy?language=pt-br. Acesso em: 13 jun. 2020.
} 
o conhecimento abstrato mais visual e prático para que as inferências pudessem ser mapeadas e servir de auxílio para a produção textual solicitada adiante.

Assim, passamos para a última sessão da UT. De maneira mais explícita, tentamos apresentar como o exercício de leitura é um constante cotejamento do eu-leitor com o eu-voz-do-texto, sendo que nessa atividade a formação identitária é constante, por isso a importância de fugir do perigo da "história única" e compreender a narrativa como uma das muitas maneiras de se contar uma mesma história. Como afirma Jouve, ambas instâncias estão relacionadas e a leitura é como esse

Espaço intermediário entre o eu do leitor e o não eu do texto, entre o sujeito que lê e o outro que escreve, entre o imaginário das representações e a realidade da linguagem, ela é esse lugar intermediário onde se persegue a construção jamais acabada da nossa identidade (JOUVE, 2004, p. 61).

É, logo, espaço privilegiado para a formação de identidades que se expressam também por meio da escrita, o que se segue nessa experiência em sala.

A continuidade da UT se dava a partir da história de Alexander McCandless, história de vida real relatada no livro de Jon Krakauer e adaptada para o cinema por Sean Penn. Ele que teve sua trajetória famosa sob o título de Na natureza selvagem (Into the wild). Para apresentá-lo aos alunos, primeiro lemos uma reportagem do jornal The guardian em que a descrição pintava Alexander em sua busca como: "stubborn, driven, selfish" [teimoso, determinado e egoísta]. Também pedimos que os alunos depreendessem, desse texto, vocabulário, novamente em uma atividade de inferência, preenchendo as definições com as palavras apresentadas para, em um trabalho detido, terem tempo de pensar com mais detalhe sobre o que foi dito pelo jornalista.

Ao finalizarem essa atividade, pedimos que expressassem suas primeiras impressões: How do you believe this man looked like? What could be his motivation to such a lifestory? [Como vocês acreditam que era esse rapaz? O que o motivaria a ter tal trajetória?]. As impressões dos alunos, com exceção dos que já conheciam o filme, aproximaram-se bastante daquela a que tinham acabado de ser expostos. A figura de Alexander tendia mais para a de alguém egoísta. Para contrastar, convidamos os alunos a assistir ao trailer do filme, no qual encontramos muito mais da perspectiva do próprio Alexander, bem como a ler duas frases deixadas por ele quando da sua morte: "I have had a happy life and thank the Lord, goodbye may God bless you all" e "Happiness is only real when shared" ["Eu tive uma vida feliz, graças a Deus, adeus e que Deus abençoe a todos" e "A felicidade é somente real quando compartilhada"]. 
Com isso, esperávamos mostrar uma outra narrativa possível acerca da mesma história. Defendendo o perigo da história única, e agora em posse de duas versões da mesma história, foi pedido aos alunos que apresentassem a sua perspectiva: Which version of Alexander would you defend as most real? Both can be true? Why do you believe so? [Qual versão de Alexander você defenderia como mais real? Ambas podem ser verdadeiras? Por quê?]. Com isso, eles puderam exercitar tanto o relato, ao defenderem uma história, quanto julgar pessoalmente a situação apresentada.

Ao chamar os alunos para a criação de uma terceira narrativa para Alexander McCandless, a ideia era começar uma familiarização com a posição de autores. Nos encaminhamos, por fim, para o terceiro nível de outridade (das vidas famosas, às vidas desconhecidas, às vidas pessoais). O outro dos outros, o próprio eu, foi inicialmente mobilizado e concluiu a UT com o exercício de sua própria alteridade. Os alunos foram convidados, ao final, a fazer seu próprio exercício de storytelling. Humans of IFA é o título da última atividade, na qual puderam criar uma história pessoal, com suas palavras, ao exercitarem o conteúdo linguístico também apreendido na UT.

Nessa atividade, que era a produção final da UT — Humans of IFA —, os alunos mobilizaram todo o vocabulário e estruturas da unidade, assim como as discussões sobre como construímos a narrativa de modo a causar determinado efeito, um sentimento no leitor e, a partir disso, pensaram a própria autoria e a outridade de si mesmos ao traduzirem-se na escrita e na língua estudada. Considerando que a proposta era que escrevessem um relato e a maioria optou por memórias atuais, como é a proposta do site, e alguns escolheram lembranças de infância. No entanto, todos escolheram memórias fora do comum, como que registrando um deslocamento dentro do cotidiano, o extraordinário dentro do ordinário da vida.

Selecionamos três redações para analisar e trazer para o nosso artigo a escrita dos estudantes $^{18}$. O primeiro foi escrito por Pedro ${ }^{19}$, aluno que viveu o continuum das duas UTs, por ter sido aluno dos níveis 2 e 4 quando foram aplicadas por nós. Leiamos o texto dele, composto por três partes: aviso, título e relato.

\footnotetext{
${ }^{18}$ Decidimos por não fazer as correções textuais para marcar as escolhas de vocabulário e as estruturas dos alunos.

${ }^{19}$ Escolhemos dar um pseudônimo os autores dos textos analisados para que haja um eu nomeado e não um apagamento do sujeito no anonimato, assim como para marcar o gênero. Reiteramos que todos os nomes de alunos que aqui aparecem são pseudônimos e que os textos foram analisados com autorização dos autores.
} 
I know I'm not the best person to tell you this story, because this story is mine and you gonna read my own perspective, but trust in me! I'm right about what I saw that night.

Light Woman

"There is no place like home", I don't agree one hundred per cent with this line thanks to that night... When I was a child, I used to play ball with my older brother inside our room, we spent hours having fun while my parents were waching $T V$. The window of our room was always broken, but that night the damage was not so big, then we could see the garden throught a small opening. When my brother and I had just finished our funning moment, the sun had already said goodbye and we had to go to the bed. Before that, my bro hold the ball and had a sit on the floor, and I stood with my back to the window. I dunno the reason, but I look trhought the small opening on the window and I saw a woman shining and floating on the grass... Immediately I told to my bro, but he laughed at me. I said that I was not kidding and I went to the window again, but this time I didn't see nothing. Then my brother saw that I was scared, so he was scared too, he dropped the ball he was holding, got up, ran into the room with my parents, and I ran too... Good thing now I can realize that my home is not haunted, actually I saw something shiny in the shape of a woman. But saw that, I know I saw. (Pedro) $)^{20}$

Escritor de ficção, Pedro já começa o texto dele dialogando com o leitor sobre o que é narrar uma história cujo referencial é a verdade, ou seja, o vivido, em um nível literário. No aviso, quando fala que é sua "própria perspectiva", ele problematiza a

${ }^{20}$ Decidimos deixar o original no corpo do texto e apresentar uma tradução em nota de rodapé, para deixar em evidência a produção textual dos alunos. Tradução nossa: "Eu sei que não sou a melhor pessoa para contar essa história, porque ela é minha e você lerá minha própria perspectiva, mas acredite em mim! Tenho certeza do que eu vi naquela noite. Mulher iluminada

"Não há nenhum lugar como nossa casa", eu não concordo cem por cento com dizer graças àquela noite...

Quando era criança, eu costumava jogar bola com meu irmão mais velho no nosso quarto, nós ficávamos horas nos divertindo enquanto nossos pais estavam assistindo TV. A janela do nosso quarto estava sempre quebrada, mas naquela noite o estrago não foi tão grande, então nós podíamos ver o jardim pela pequena abertura. Quando eu e meu irmão tínhamos acabado nosso momento de diversão, o sol já havia se posto e nós fomos para a cama. Antes disso, meu mano segurou a bola e se sentou no chão, e eu fiquei de pé de costas para a janela. Eu não sei o motivo, mas eu olhei pela pequena abertura e vi uma mulher brilhando e flutuando na grama... Imediatamente contei ao meu mano, mas ele me zombou. Eu disse que não estava brincando e fui até a janela de noto, mas dessa vez não vi nada. Como meu irmão viu que eu estava assustado, ele ficou também, largou a bola que estava segurando, levantou, correu para o quarto dos nossos pais, e eu corri também... Uma boa coisa é que eu posso perceber agora é que minha casa não é assombrada, eu simplesmente vi alguma coisa brilhante no formato de uma mulher. Mas eu vi aquilo, eu sei que vi." (Pedro)

Revista X, v. 16, n. 4, p. 1011-1037, 2021. 
perspectiva única do texto - e da vida - e explicita que é uma leitura possível do evento, fazendo um pacto com o leitor, algo que faz parte do contar-se na escrita. Inclusive, é uma perspectiva deslocada, já que a história foi vivida na sua infância e narrada na fase adulta, ou seja, passou por uma transformação de olhar e de língua. Além disso, essa distância temporal faz com que ele ressignifique o medo da figura brilhante e de sua casa ser assombrada. $\mathrm{O}$ que era um acontecimento extraordinário na infância passou a ser ordinário e memória de criança com imaginação fértil.

A segunda narrativa, de Julia, também rememora a infầncia:

It was a sunny day and it would become a funny memory. My family and I were on the beach and we walked a lot trough a trail to arrive there. Then, when we got it, we enjoyed the landscape, but until I have decided to play in the sea. Well, I was nine years old, specially boring and I lost one of my slippers at the seashore. Due to it, I started to cry and my father did resolve to get the slipper. However, the sea was in a bad mood and the waves were turbulent. Then, the waves took my father close the stones and the things started to get dangerous. All the people on the beach were looking to the fight between the man, the sea and the slipper. At that moment I was crying because I did not want to back barefoot to home and also because my father could die! But, the slipper stopped fighting and my dad won it! After the surrender of the slipper, everybody applauded the hero of the day. (Julia) ${ }^{21}$

Assim como Pedro, Julia escolheu uma memória que marcou a infância pelo medo, mas, no lugar do extraordinário, há um medo infantil e um risco de vida. A escolha do ponto narrativo é interessante porque está entre uma imagética do eu mais infantil e o eu de hoje, como no fechamento do texto, quando ela recupera seu pai como o "herói do dia". Além disso, há um tom épico típico dos olhos de uma criança que acha que tudo é grande, a exemplificar pela caracterização do evento como uma "luta" entre o pai, o mar e o chinelo. Nessas duas narrativas de rememoração da infância, vemos a construção da alteridade de si mesmos pela linguagem e pela língua, de modo que a implicação

\footnotetext{
${ }^{21}$ Tradução nossa: "Era um dia ensolarado que se transformou em uma memória engraçada. Minha família e eu estávamos na praia e andamos um monte por uma trilha para chegar lá. Então, quando chegamos, apreciamos a paisagem até que eu decidi brincar no mar. Bem, eu tinha nove anos, estava entediada e perdi um dos meus chinelos na água. Por causa disso, comecei a chorar e meu pai resolveu procurar meu chinelo. No entanto, o mar estava bravo e as ondas estavam turbulentas. Então, as ondas levaram meu pai perto de umas pedras e as coisas começaram a ficar perigosas. Todo mundo na praia estava assistindo à luta entre o homem, o mar e o chinelo. Naquele momento eu estava chorando porque eu não queria voltar descalça para casa e porque meu pai poderia morrer! Mas o chinelo parou de lutar e meu pai o pegou! Depois da captura do chinelo, todo mundo aplaudiu o herói do dia." (Julia).
}

Revista X, v. 16, n. 4, p. 1011-1037, 2021. 
subjetiva traz a ressignificação do próprio eu que escreve, porque precisa pensar como narrar aquele outro que já foi (e hoje faz parte do) eu que se escreve.

Por fim, o texto de Marina, que relata um evento recente e inaugural de sua vida acadêmica:

I'm going to talk about a conference that I went to this month. It was my first time going to a scientific conference to participated as a listener and as a presenter. First of all, in order to present I had to write an article and submitted it to the examination border. I was approved. As a result, I had to schedule myself to be able to go to São Paulo. So I bought the flight tickets and made a reservation at an Ibis in advance. However, nothing went to the way I thought it would go. For instance, I missed my flight and had to bought a new and expensive ticket on that day. Above all, they do not had ticket to the right airport. I had to get to Congonhas, but the new ticket was for Guarulhos. Therefore, I took an Uber all way over Guarulhos to got to Congonhas. That day I was exhausted. In addition, when I finally got to the Ibis where I made a reservation they said they have some problems on theirs system and apparently my reservation was wrong. I literally thought I was about to be sent to the street with nothing but my baggages. To summarize, luckily they had a small room so I could stayed. This is a short description of my first and tragic conference experiences. (Marina) ${ }^{22}$

A voz de Marina é bastante diferente das vozes dos dois outros textos: é uma voz adulta. Ao escolher uma experiência de um congresso científico, Marina desloca a formalidade e a ausência da subjetividade no mundo acadêmico para o relato dos "ossos do ofício" de participar de um evento em outra cidade, vivenciado por todos os pesquisadores, mas deixado mais abaixo das notas de rodapé dos textos acadêmicos. Pensando nisso, é interessante o uso confortável da primeira pessoa para recuperar sua vida, visto que em contextos de ensino não somos tão estimulados a escrever em primeira

${ }^{22}$ Tradução: "Vou falar sobre um congresso que fui neste mês. Foi minha primeira vez que participei de um congresso científico como ouvinte e apresentadora. Primeiramente, para apresentar eu precisava escrever um artigo e submetê-lo para avaliação da banca. Fui aprovada. Como resultado, eu me organizei para ir para São Paulo. Então eu comprei minha passagem de avião e depois fiz uma reserva no Ibis. Porém, nada aconteceu como eu planejei. Eu perdi meu voo, por isso tive que comprar naquele dia uma passagem mais cara. Para piorar, eles não tinham passagem para o aeroporto certo. Eu tinha que ir para Congonhas, mas a nova passagem era para Garulhos. Assim, eu peguei um uber de Garulhos para Congonhas. Foi exaustivo. Além disso, quando eu finalmente cheguei ao Ibis onde eu tinha feito a reserva, eles disseram que tiveram alguns problemas no sistema e aparentemente minha reserva estava errada. Eu simplesmente pensei que seria enviada para a rua com nada além das minhas malas. Para resumir, felizmente eles tinham um pequeno quarto onde eu pude ficar. Essa é uma pequena descrição da minha primeira e trágica experiências em congresso acadêmico." (Marina).

Revista X, v. 16, n. 4, p. 1011-1037, 2021. 
pessoa de forma a nos colocarmos efetivamente dentro dos textos. Também, o texto demonstra que a aluna colocou em uso os conectivos, que era um dos focos da unidade.

A partir da leitura dos relatos autobiográficos dos alunos, que aliam passado e presente em seus textos, podemos recuperar o que diz Gloria Park (2011) sobre sua experiência docente no Cultural and Linguistic Autobiography Writing Project (Projeto de escrita autobiográfica cultural e linguística): esse tipo de escrita reflexiva e pessoal pode ajudar os estudantes a relacionarem o passado e o presente e pensarem o futuro, inclusive um porvir em mais uma língua. Nesse contexto, pela reflexão da própria subjetividade, engajam-se em

[...] práticas dialógicas com eles mesmos, seus textos, e uns aos outros conforme eles continuem refletindo sobre seus objetivos relacionados à aprendizagem e ao ensino de língua inglesa em contextos socioculturais, sócio-históricos e sociopolíticos maiores". (PARK, 2011, p. 168, tradução nossa). ${ }^{23}$

\section{MORTE E RENASCIMENTO: REFLEXÕES FINAIS}

Pensando a escrita como um ensaio embrenhado de storytelling, compartilhamos o processo de construção, reelaboração e aplicação de nossas UTs ao longo do período em que vivemos o IFA/FIVU, explorando a língua enquanto cultura e as subjetividades dentro do material e da sala de aula, assim como as identidades deslocadas, híbridas e, para ressoar Bhaba (1998), enquanto habitantes desse terceiro espaço intercultural que é o habitar línguas e o choque de culturas e sentidos. A riqueza da variedade e complementaridade de diferentes identidades em sala de aula está diretamente ligada ao ensino da língua se compreendermos a experiência linguística como um exercício narrativo que está e vai muito além do contexto de aprendizagem. A consciência da utilização da língua, em prol de uma expressão sociointeracionista, confere aos alunos um protagonismo em sala - e fora dela, na comunicação - que edifica o interesse no aprendizado, que por sua vez, se apresenta muito mais efetivo. A complexidade das existências humanas se apresenta implicada no aprendizado e essa consideração nos parece essencial para um bom trabalho em aula.

\footnotetext{
${ }^{23}$ No original: "dialogic practices with themselves, their texts, and one another as they continue to reflect on their goals related to learning and teaching English situated in broader sociopolitical, sociohistorical, and sociocultural contexts." (PARK, 2011, p. 168).
} 
Um dos pontos importantes para a nossa jornada e para a escrita desse texto foi a alteridade. Tanto no co-teaching quanto na reformulação de nossos materiais a partir de comentários e orientações de materiais outros, das professoras, dos outros praticantes e, claro, dos alunos, que nos ensinaram muito no processo de estarmos nos formando professoras. A alteridade também perpassou a nossa escrita, porque, apesar de não termos entrado em sala juntas, perguntamos sobre e comentamos o relato uma da outra, para pensarmos juntas nossas experiências pelo olhar da outra, de forma que pudemos aproximar esse co-writing do co-teaching, já que o sujeito se anuncia e enuncia quando interpelados por outros que se dizem "eu” e assim nos fazemos: eu/nós/we.

\section{REFERÊNCIAS}

ADICHIE, Chimamanda Ngozi. O perigo de uma história única (TED TALK). 2009. Disponível em: https://www.ted.com/talks/chimamanda_ngozi_adichie_the_danger_ of_a_single_story?language=pt-br. Acesso em: 13 jun. 2020.

ADICHIE, Chimamanda Ngozi. Americanah. Tradução de Julia Romeu. São Paulo: Companhia das Letras, 2014.

ANZALDÚA, Glória. Borderlands/La frontera: la nueva mestiza. Tradução de Carmen Valle. Madrid: Capitán Swing libros, 2007.

BAKHTIN, Mikhail. Estética da criação verbal. São Paulo: Martins Fontes, 2000.

BHABHA, Homi. O local da cultura. Belo Horizonte: Editora UFMG, 1998.

GIMENEZ, Telma. "Eles comem cornflakes, nós comemos pão com manteiga": espaços

para reflexão sobre cultura na aula de língua estrangeira. In: ENCONTRO DE PROFESSORES DE LÍNGUAS ESTRANGEIRAS, 9. 2002, Londrina. Anais [...]. Londrina: APLIEPAR, 2002, p. 107-114.

HALL, Stuart. A identidade cultural na pós-modernidade. Tradução de Tadeu Tomaz da Silva. Rio de Janeiro: D\&PA, 2006.

JANZEN, Henrique Evaldo. Concepções de cultura e o ensino de línguas estrangeiras modernas. In: SCHMIDT, Maria Auxiliadora; GARCIA, Tânia Maria F. Braga; HORN, Geraldo Balduíno (org.). Diálogos e perspectivas de investigação. Ijuí: UNIJUÍ, 2008, p. 63-76. 
JANZEN, Henrique Evaldo. O papel do interlocutor na elaboração e reelaboração de unidades temáticas no ensino de Línguas Estrangeiras Modernas. Estudos Linguísticos, v. 40 n. 2, maio/ago. 2011, p. 661-671.

JANZEN, Henrique Evaldo. A Alteridade: um olhar intercultural. In: STOLTZ, Tânia; GUERIOS, E. (org.). Educação e Alteridade. São Carlos: EdUSCar, 2010, p. 211-222.

JOUVE, Vincent. A leitura como retorno a si: sobre o interesse pedagógico das leituras subjetivas. Tradução de Neide Luzia de Rezende. In: OUXEL, Annie; LANGLADE, Gerárd; REZENDE, Neide L. Leitura subjetiva e ensino de literatura. São Paulo: Alameda, 2013.

LISPECTOR, Clarice. A descoberta do mundo. Rio de Janeiro: Rocco, 1999.

MATSUDA, Aya; FRIEDRICH, Patricia. English as an international language: a curriculum blueprint. World Englishes, v. 30, n. 3, p. 332-344, 2011.

MOLLOY, Sylvia. Viver entre línguas. Tradução de Mariana Sanchez. Belo Horizonte: Relicário, 2019.

MORRISON, Toni. A origem do outro. Tradução de Fernanda Abreu. São Paulo: Companhia das Letras, 2017. (Ebook).

NUNAN, David; CHOI, Julie. Language and culture: reflective narratives and the emergence of Identity (ESL \& Applied Linguistic Professional Series). New York: Routledge, 2010.

SILVA, Leticia Pilger da. O realismo formal na aula de língua estrangeira. Revista X. v. 13, n. 2, p.93-110, 2018.

PICANÇO, Deise. A língua estrangeira no país dos espelhos: uma reflexão sobre o limbo metodológico. Educar, n. 20, 2002, p. 165-182.

PARK, Gloria. Adult English Language Learners Constructing and Sharing Their Stories and Experiences: The Cultural and Linguistic Autobiography Writing Project. Tesol. v. 2, n. 2, 2011, p. 156-172.

SAER, Juan José. O conceito de ficção. Tradução de Joca Woolf. Sopro, v. 15, p. 1-4, 2009. 
SANTOS, Jovania. Proposta de critérios para elaboração de unidades temáticas e de enunciados de tarefas em contexto de ensino de PLE no CELIN-UFPR. 2014. Dissertação (Mestrado em Estudos Linguísticos) — Universidade Federal do Paraná. Curitiba, 2014. 149f.

SILVA, Renato C. O professor de línguas, o PNLD, o livro didático de línguas e outros materiais didáticos. Revista A Cor das Letras. v. 18, n. 3, p. 138-153, set./dez. 2017, p. 138-152.

SMITH, Emily Esfahani. There is more to life than being happy. TED TALK. 12min.18s. Disponível em: https://www.ted.com/talks/emily_esfahani_smith_there_s_ more_to_life_than_being_happy\#t-726245 Acesso em: 13 jun. 2020.

\section{ANEXOS}

Anexo 1: Biography — atividade Guess Who (3 etapas).

1) I AM

He was born in São Paulo.

He plays soccer since he was eleven years-old.

$\mathrm{He}$ is famous for his unusual haircuts.

He has a son.

He worked for a Spanish team until 2017 but now he works for a French team.

He dated a Brazilian actress.

His favorite food is French fries.

6) I AM

was born — in the countryside of Santa Catarina — he

as — he — blacksmith — my - worked — a — grandfather — his — with

to - actress - married - he - and — is - a - Brazilian - model

cooking - he - a - show - presents

twin - has - sons - he

a perfect — he — is considered — man — because he — cleans — cooks — the house — builds stuff — looks after his kids

Think about a famous person and, firstly, write 1 to 4 sentences about him/her:

Name:

Fact 1:

Fact 2:

Fact 3:

Fact 4:

Then, read out loud your tips to a classmate and see if he or she is finds out who the person is! 


\begin{abstract}
Anexo 2: Storytelling — atividade 1
"I'm doing a review of last year. I'm looking at all the goals I set and whether I managed to achieve them. A big one for me was that I finally managed to get my driver's license. It's a little embarrassing because I'm well past that age, but I've always been terrified of driving. So I signed up for some lessons. I studied hard. I took extremely meticulous notes. Then I went to the testing center with my driving instructor. They assigned me a real hard faced guy from Eastern Europe. [...] So I started off pretty nervous. I messed up almost immediately and made a rolling stop. [...] The test seemed to go on forever. I couldn't charm the guy. I tried to make conversation but he was silent the entire time. Then after we finished, he made me sit outside his office for an eternity. But finally he came out and told me that I'd passed! It was such a relief! I haven’t driven since."

Fonte: https://www.humansofnewyork.com/post/173342050291/im-doing-a-review-of-last-yearim-looking-at. Acesso em: 10 jun. 2020.
\end{abstract}

Recebido em: 27 jul. 2020.

Aceito em: 07 out. 2020. 